REVISTA NORMAS, N. ${ }^{\circ}$ 5, 2015, PP. 133-152 (ISSN: 2174-7245)

(RECIBIDO: 20-03-2015. EvALUADO: 20-05-2015. ACEPTADO: 15-06-2015)

DOI: $10.7203 /$ Normas.5.6816

\title{
CURRENT APPROACHES TO ORTHOGRAPHY INSTRUCTION FOR SPANISH HERITAGE LEARNERS: AN ANALYSIS OF INTERMEDIATE AND ADVANCED TEXTBOOKS
}

\author{
ENFOQUES ACTUALES PARA LA INSTRUCCIÓN ORTOGRÁFICA DE ESTUDIANTES \\ DE HERENCIA ESPAÑOLA: UN ANÁLISIS DE \\ LIBROS DE TEXTO DE NIVELES INTERMEDIO Y AVANZADO
}

\author{
Clara BURGO \\ Loyola University Chicago
}

ABSTRACT:

As it is well known, heritage learners of Spanish have an advantage in oral production and aural comprehension over L2 learners. However, due to their lack of formal instruction in Spanish, their linguistic weaknesses lie in their literacy skills (reading and writing). In terms of writing skills, students mainly struggle with orthography issues (accentuation and spelling) and larger literacy skills (e.g. developing a thesis or organizing ideas). However, there is an important gap in the literature regarding orthographic acquisition since most of the research in the field that focuses on form instruction has predominantly been on grammar acquisition (Anderson, 2008; Montrul and Bowles, 2008; Potowski, 2005, among others). In fact, despite the increasing amount of textbooks with an emphasis on the writing process addressed to this student population, to my knowledge there has not been a study on the current approaches of Spanish heritage learners' textbooks for orthography instruction. After analyzing four popular textbooks for Spanish heritage learners, it can be deduced that the lack of research in this area perpetuates the maintenance of traditional non-communicative explicit instruction of orthography through drills after an explicit explanation of the rules of both accentuation and spelling. However, new textbooks shed some light on the implementation of focus on form teaching techniques commonly used in the L2 classroom such as input-output activities.

KEY WORDS: Spanish heritage learners, orthography instruction, communicative instruction, focus on form teaching techniques. 


\section{INTRODUCTION}

The strengths (oral production and aural comprehension) and weaknesses (literacy skills) of these learners in comparison to L2 learners are well known. One of the main weaknesses within these students' writing skills is accentuation and orthographic competence due to the lack of exposure directly linked to literacy. In fact, spelling skills provide support for reading and writing (Apel, 2009). However, most research on teaching techniques for heritage learners have focused on grammar or sociolinguistic teaching approaches instead of specific techniques to teach spelling or accentuation. In this article an analysis of four recent intermediate and advanced Spanish heritage textbooks is presented in order to describe current approaches to teaching orthography (spelling and accentuation). The main research question that this article intends to respond to is the following: Are the approaches used in these textbooks still traditional or is there a tendency to be communicative (emphasizing interaction)?

\section{REVIEW OF THE LITERATURE}

Unfortunately there is a big gap in the literature concerning Spanish heritage learners' spelling and accentuation instruction. Mikulski (2006) conducted a questionnaire on the importance of learning goals for Spanish heritage learners and found that there was unanimity among all of the heritage learners she had polled in ranking the improvement of spelling and grammar as a very important learning goal for the course and where they considered having made more progress than in other skills. Nevertheless, there is no information about how they acquired or were taught orthography. She concluded that the results suggested a generalized concern for written accuracy. Although accentuation errors did not impede reading comprehension, students were very motivated to learn the rules due to their language backgrounds. Heritage learners were quite aware of their linguistic needs and felt very motivated to work on their writing skills and grammar accuracy.

Beaudrie (2007) performed an experimental study on the acquisition of written accents in L2 Spanish learners. Results showed that the problem was identifying the stressed syllable as it is for native speakers (Urria, 1988) and heritage learners (Carreira, 2002) but L2 learners did not find many difficulties when marking the written accent correctly. Future research might reduplicate this study with Spanish heritage learners that seem to have problems with both identifying the stressed syllable and marking the written accent correctly. What seems interesting is the lack of attention paid to accentuation instruction, not only in Spanish heritage courses as earlier mentioned but also in L2 Spanish courses. Since the 70s, accentuation instruction has been limited to explicit presentation and practice of the rules (Beaudrie, 2007; Henry, 1983; Teschner, 1971). Interestingly, acquiring accentuation is highly complex for both L2 and heritage learners, it being the 
most frequent orthographic error made by these learners (Grompone, 1982). The rationale behind this complexity lies in two processes: recognition of the stressed syllable (acoustic phenomenon) and the application of the stress rules (Henry, 1983). Lord (2002) carried out a study with basic, intermediate and advanced L2 Spanish learners. She found that at the basic and intermediate levels, students seemed to ignore the written accent since they did not use it in their production. Nevertheless, this was not the case for advanced learners.

Regarding instructional techniques for accentuation, Urria (1988) suggested several steps:

a) Oral analysis of the word in order to achieve aural discrimination.

b) Forming acoustic patterns of the discriminated phenomena that facilitate their recognition.

c) Studying written accent rules.

d) Forming visual patterns to insert the written accent automatically.

The key question lies in whether accentuation for L2 learners is acquired through the memorization of lexical entries, through an analogical process of already learned lexical entries, or through rules (Guion, Harada and Clark, 2004). Lord (2002) found that known words are learned through lexical entries and their correct accentuation patterns. Unknown words, however, are acquired via accentuation rules or analogy with existent forms in their lexicon.

One of the causes for typical errors derives from English transfer errors such as vowel misspellings, since English has a broader vowel system (Beaudrie, 2012; Tapfer, 2013). However, Lord (2002) claims that there are similarities in English and Spanish such as marking the primary accent in the last three syllables that does not make accentuation particularly difficult for them to acquire. In order to acquire it, students need to be able to correctly identify the stressed syllable (Wieczorek, 1991).

Concerning spelling, Justicia, Defior, Pelegrina and Martos (1999) performed a study with Spanish monolingual children in which they had to write a story on any topic with no time limit and they classified all the spelling errors into categories: substitution of graphemes, omission, addition, grapheme rotation, inversion, or order and synthesis. They found that more than half of the total errors were of the substitution type, e.g. baca for vaca.

To my knowledge, the only study on spelling with adult heritage learners of Spanish is that of Beaudrie (2012). She carried out a study with university students in a composition Spanish heritage course and chose a free writing strategy rather than dictation to do an error analysis on the spelling of familiar words. Results showed that almost all common errors (98\%) were of the substitution type. Among these, most of them were 's' for 'c' followed by ' $s$ ' for ' $\mathrm{z}$ '. e.g. hise/ hice; empesar/empezar. Other frequent errors were /s/, /b/ (specifically, the overuse of ' $s$ ' and ' $v$ ') and the omission of ' $h$ '. Therefore, it would be recommended to focus on the spelling rules that would disambiguate the uses of these graphemes. Beaudrie suggests focusing on the most recurrent errors found in her study: 
hacer, haber, hasta, ir, deber, estar, a, and era, together with the -aba ending in the imperfect tense.

Interestingly, the largest number of misspellings was written accents. This accounted for more than two thirds of all spelling errors, specifically the omission of accents in verb tenses (with the preterit being the most recurrent one) and when the stress is in the ultimate and antepenultimate syllables and with hiatus (e.g. hablo vs. habló). One curious finding of this study is that overall students demonstrated command of Spanish orthography despite their lack of formal instruction in Spanish.

Since well-known L2 techniques such as processing instruction (input based; learners process meaning before processing form) and dictogloss (output based text reconstruction) have been successfully implemented in the heritage classroom for grammar instruction, perhaps they could be also transferred to the area of spelling instruction in addition to other recently proposed strategies such as dictation (Pyun and Lee-Smith, 2011).

\section{SimilaritiES AND DIFFERENCES BETWEEN L2 AND HERITAGE LEARNERS REGARDING ORTHOGRAPHY ACQUISITION}

Many of the common orthographical errors made by heritage learners do not occur in L2 learners, who can write the words that they know mainly because of their experience with formal instruction in the language. Bowles (2011) found that L2 Spanish learners were very accurate with spelling and accent placement whereas heritage learners were not in a mixed classroom at an advanced level of Spanish. Although orthography should be taught to both student populations, heritage learners need more work on written accuracy (Kagan and Dillon, 2001). These errors are produced by their reliance on verbal cues when writing and spelling. Therefore, these learners' verbal advantage can have a negative impact on their orthography (Loewen, 2008). Because of their extended exposure to oral discourse, they tend to write as they speak. That is, there is a transfer of their pronunciation into their writing (Bermel and Kagan, 2000; Chevalier, 2004; H.H. Kim, 2001; Loewen, 2008). For heritage learners of Spanish, the same trend is found. In fact, there is research that shows that when both student populations are mixed in the same classroom, heritage learners rely on their L2 classmates for orthography (spelling and accentuation) whereas L2 learners rely on the heritage ones for vocabulary and grammar (Bowles, 2011).

In terms of orthography, it has been shown that Spanish heritage learners tend to confuse homophones in their dialects such as ' $c$ ' and ' $s$ ' and the omission or presence of ' $h$ ' due to its silent sound. As a Spaniard teaching heritage speakers for many years, I found that students did not perceive dialectal variation such as the phonological distinction of 'c' and ' $s$ ' in my dialect when doing dictations. It would be interesting to see if there were differences in their spelling of ' $c$ ', ' $z$ ' versus ' $s$ ' (the distinction /0/) when dictation is performed by a Spaniard or a seseist native speaker. This is an extremely familiar 
phenomenon for any SHL teacher in the United States, and this particular spelling problem is addressed in many SHL textbooks.

On the other hand, the identification of the stressed syllable is one of the most difficult challenges for both L2 and heritage learners (Beaudrie, 2007; Carreira, 2002). As mentioned earlier, it is a requirement for marking correct written accents (Urria, 1988).

Explicit rule presentation has been found to be beneficial for both L2 and heritage learners, above all for the instruction of target forms that are less salient (DeKeyser, 1995; Ellis, 1993; Lyster, 2004; Pyun and Lee-Smith, 2011; Robinson, 1996). Dictation for orthography acquisition might be one of these as proposed by Pyun and Lee-Smith (2011). Although it is not a new teaching technique, there is not much research on this in the L2 classroom. It is considered to be an adequate technique for languages with complex spelling and sound systems (Davis and Rinvolucri, 1988). Dictation makes students decode the speech sounds and recode them when writing. The authors consider this a beneficial technique since they are engaged in active learning while creating visual memory of the target language and follow-up self-correction exercises. Dictation involves the processing of aural and visual information and it helps heritage learners to make connections between sounds and forms (Pyun and Lee-Smith, 2011). In short, it is a learning tool that enhances spelling and grammar accuracy through learners' awareness of these skills (Valette, 1964; Whitaker, 1976) so it seems to be a promising technique, ideal for both L2 and heritage learners since it addresses the main weakness of the latter.

\section{PEDAGOGICAL IMPLICATIONS OF RESEARCH ON ORTHOGRAPHY}

Teaching spelling is one the most challenging issues in the classroom for there is not much research on the development of spelling in adults. Many teachers are unaware of the best teaching techniques for spelling, and traditional approaches that are used in most of the textbooks are drills that students do not find motivating (Brown, 1990). Many Spanish heritage learners' curricula present a general overview of orthographic rules in Spanish instead of placing emphasis on the common spelling errors made by these learners (Beaudrie, 2012). Beaudrie proposes a more focused corpus-based approach to spelling instruction since the typical errors that Spanish heritage learners are facing are limited. Moreover, this reduces time costs for instruction considering the scarce time availability that can be devoted to spelling in the heritage learner classroom. In order to utilize this approach, two factors have to be considered: word frequency and the list of the most problematic graphemes for students.

Beaudrie's (2007) research shows that written marks instruction was not beneficial for L2 Spanish learners. Students might have serious difficulties writing the accent when the stressed syllable is not indicated. Therefore, she concludes that it would be necessary to focus on the perception and identification of the stressed syllable before teaching the 
accentuation rules. Moreover, it is important to know whether the problem is identification (like native speakers) of the stress or also in its perception. Since she considered the accentuation rules to be easy to acquire, she suggested accentuation instruction from the very basic levels. Thus, accentuation errors would be attenuated since written accents would be used as facilitators for writing and phonology.

There have been some attempts to suggest effective instructional techniques to overcome heritage learners' common orthographic errors. Pyun and Lee-Smith (2011) proposed using dictation as a learning device through a computerized dictation program and in-class dictation activities for Korean heritage learners. These techniques were found to work by sensitizing these learners to written forms and thus making connections between sounds and written forms. Additionally, students were very motivated so they provided positive feedback regarding dictation as a learning tool and their sense of achievement. They preferred a focus on general orthography rather than just on the common misspelling errors. Pyun and Lee-Smith propose focus-on-form teaching strategies such as dictation, explicit explanations of errors and follow-up correction activities to increase students' awareness of orthography so that they can notice recurrent errors. Despite the effectiveness of this technique, instructors should calibrate the time costs of it at expense of teaching other skills, above all for L2 learners since it is not one of their main weaknesses.

Reading and spelling are found to be much related since they draw from the same orthographic knowledge bases (letters and mental representations of words) (Ehri, 2000). Thus, reading would help heritage learners with their spelling. Beaudrie (2012) proposes emphasis on diacritics' instruction and verbal forms as a means of reducing around $50 \%$ of the current accentuation misspellings. In fact, the regular stress pattern of preterit and imperfect would facilitate the teaching of these tenses.

Since this is a new emerging research field, there are not many proposals for pedagogical purposes. Nevertheless, we could consider implementing instructional techniques for orthography as an alternative to Beaudrie (2012) that have been used in other languages such as English. Even though English has a larger number of inconsistencies in grapheme-phoneme relationships, research has pointed towards an inductive or exploratory approach with large amounts or reading and writing opportunities for practice as well as spelling instruction (Templeton and Morris, 2001).

\section{ANALYSIS OF INSTRUCTIONAL TECHNIQUES FOR ORTHOGRAPHY PRESENTED IN RECENT SPANISH FOR HERITAGE LEARNERS TEXTBOOKS}

As Beaudrie (2012) argues, Spanish heritage language textbooks tend to present the complete set of the Spanish orthographic rules from a traditional approach rather than just focusing on the common spelling errors that these learners find challenging. Therefore, four current and popular textbooks in U.S. higher education institutions at the intermediate and 
advanced levels are analyzed regarding their instruction of orthography (spelling and accentuation) in order to explain how far Spanish heritage instruction has progressed on this issue in the last fifteen years. The textbooks under analysis in this article in chronological order are: Entre mundos: An Integrated Approach for the Native Speaker (Alonso-Lyrintzis and Zaslow, 2003); Sí se puede: Un curso transicional para hispanohablantes (Carreira and Geoffrion-Vinci, 2008), Conversaciones escritas: Lectura y redacción en contexto (Potowski, 2010) and El Mundo 21 hispano (Samaniego et al. 2014).

\subsection{Entre mundos: An Integrative Approach for the Native Speaker}

Entre mundos follows an innovative four-skill task-based approach that tries to bridge the heritage speaker's oral experience with the written forms and introduces the dialectal variation of the Spanish-speaking world. The first chapter starts with syllabification and common spelling problems under grammatical objectives. Orthography does not have a separate category but rather it is a subsection of the grammatical goals. The problematic sounds that are firstly presented are $[\mathrm{s}],[\mathrm{b}],[\mathrm{x}],[\mathrm{y}]$ and $[\mathrm{k}]$ and their corresponding graphemes with examples. There is an audio dictation activity thematically integrated with the topic of the chapter (getting to know each other) and a self-awareness guided activity to compare the instructors' answer and the students' results so that they can focus on their spelling errors and reflect upon them. Then, the rules are presented after this activity with follow-up questions to help students discover the rationale behind these problematic spelling errors and those due to English transfer. Right after, the alphabet is introduced with proper nouns examples and the practice consists of an input activity of name recognition and an output activity that promotes interaction with other classmates. Nonetheless, accentuation rules are presented in a very traditional way with a list of rules and a drill activity of syllable division. In the second chapter, an orthographic analysis is integrated as a follow-up activity of the study of the present tense by asking questions about the conjugation chart and the spelling changes. Identifying the stressed syllable is the key point of accentuation in this chapter and a deductive approach is used to categorize words depending on the stressed syllable. The strategy used for stress identification consists of reading a list of words. However, the only hint given is that the stressed syllable is the most intense one, which may not be very clear for students.

In the third chapter, the focus is on capitalization, punctuation and written accentuation on the words with the stress on the last syllable. Noticing strategies are used to present the stressed syllables (list of words with bolded stressed syllables). Through a question- answer format, it is expected that students can induce the rule behind the written accentuation of the last syllable before the actual rule is explicitly mentioned. For punctuation, a traditional non-communicative approach is adopted where a punctuation drill follows the explanations. After presenting capitalization, a dictation is used as a 
communicative input activity about the importance of English in the world. Then, students must correct capitalization errors in a text without much guidance.

In chapter four, written accents are presented for the penultimate syllable of a word in the same way as in the previous chapter: noticing bolded syllables and question-answer format to deduce the accentuation rule. Finally, the rule is explained.

In chapter five, we can find a review of the accentuation rules presented in the previous two chapters before they add those of the antepenultimate stressed syllables. Once all of the accentuation rules in terms of stressed syllables are covered, they conclude the accentuation instruction with diacritics. The review is practiced through activities that promote reading aloud list of words, underlining the stressed syllables to categorize words according to the stressed syllable. Through a question-answer format, students are expected to deduce the accentuation rules. That is what is explicitly mentioned in the instructions for the stress on the antepenultimate syllable. Finally, the rules are clearly stated. The chapter finishes with the presentation of diacritics through notes with examples and their differences in meaning and the use of the written accents, and the practice consists of explaining the rationale behind the use of these words in context. Then, a traditional exercise is used to practice the use of written accents in sentences. In chapter six, the preterit is included to talk about an important past event in the student's life. After the form and uses are explained, there is an analytical guide to make students become aware of the accentuation rules in the use of the preterit. Through a question-answer format and fill-inthe-blank sentences, rules on the accentuation in preterit forms are completed by the students. In chapter seven, formal commands are explained to give orders. After some practice with formal and informal commands, there is a spelling analysis of the accentuation on commands. Students are expected to explain why there are written accents and deduce the rules. There are other common spelling problems for commands such as c/z, $\mathrm{g} / \mathrm{gu}$. c/qu, and questions are asked to lead students to become aware of the rules. Next, accentuation in diphthongs is explained through traditional activities of placing accents and explaining differences in meaning among diacritics. Then, the rules for possessive adjectives are presented with a table, and a deductive approach follows for practice to figure out the rules by analyzing examples. In chapter eight, a spelling analysis follows the subjunctive forms. In chapter nine, there is a review of punctuation signs within a communicative approach: there is the last will of the character of a mini-drama with no punctuation. There is also a communicative follow-up question to assess meaning. In chapter ten, there is a spelling review through a communicative activity (writing a letter), where students have to correct the errors and communicative questions are also asked. However, for a review of accentuation, the focus is on metalinguistic knowledge of accentuation rules. Then, there is a communicative activity on spelling with a journal ad without accents that students need to insert, along with communicative questions. In chapter eleven, the future is presented, and again focused questions are asked to guide students to deduce the accentuation rules in the future forms. Finally, in chapter twelve, the 
conditional is presented and the same guided approach is used for accentuation awareness. In chapter fourteen, past subjunctive is presented with the same guided approach as well.

\subsection{Sí se puede}

Sí se puede is described as a transitional course for Spanish heritage speakers with little or no previous formal instruction. Emphasis is placed on orthography and the rules of accentuation as well as grammar, morphology and syntax. This textbook uses a contentbased framework through reading and writing activities to improve students' ability to communicate ideas from casual to academic Spanish. There is a focus on linguistic register and functional structure, transfer skills from English to Spanish, and cultural contributions of Latinos in United States. At the beginning of each chapter, clear goals are listed divided into skills/categories such as culture, grammar, orthography, register, and reading and writing strategies.

Interestingly, in the first chapter syllabification is included within the grammar goals. However, in the second chapter, accentuation is included in the orthography goals as expected. Regarding syllabification, rules are presented in an explicit form and the followup activities require a metalinguistic awareness of syllabification where students have to divide the words into syllables and explain why they divided them in that way in order to raise their awareness. There are several input activities for syllabification and orthography: e.g. in the last activity, students have to deduce the rule behind the formation of diphthongs. Regarding orthography, rules of punctuation and use of lower case and capitalization compared to English are presented first. An input reading activity is used via a contrastive approach between English and Spanish capitalization and a matching input activity for punctuation symbols and their corresponding names. Then, these activities are followed by a summary of the main differences between English and Spanish punctuation rules. To end this section, there is a translation input activity as a review. Despite these communicative tasks with comprehensible input and the focus on English-Spanish differences specifically intended to address the linguistic challenges for these students, it seems much metalinguistic knowledge is expected from students for whom this is probably their first course of formal instruction in Spanish.

As previously mentioned, accentuation is introduced in the second chapter. The authors start with an introductory explanation of the importance of accentuation for Spanish heritage learners. According to students, this is one of the most important learning goals of this course, despite the fact that they highlight its low communicative value in most cases. There is an emphasis on understanding accentuation as a long process that requires plenty of practice and correction before it becomes automatic and easy to handle (p. 39). As the authors clearly explain, there are two skills that need to be mastered in order to acquire accentuation: detecting the prosodic accent (the stressed syllable) and knowing the spelling rules underlying accentuation. Finally, they propose automatizing the rules through 
practice. These two rules are disclosed focusing on the main challenges these students face like the recognition of the stressed syllable. Therefore, they propose useful tips for them such as placing more emphasis on it or making it longer than the other syllables. Under the categorization of the words according to the stressed syllable, the authors opt for a traditional explanation as expected in a language arts textbook for native speakers instead of focusing on the most problematic aspects for heritage speakers. In the same vein, the activities chosen for practice are mainly based on assessing students' metalinguistic categorization of words into agudas, llanas, and esdrújulas. Once students practice this, accentuation rules are presented and drill activities are used for practice under the title $i A$ ver qué aprendiste!. At the end of this section, there is a brief mention of accentuation of monosyllables with one single example. Then, as a summary ¡A ver qué tanto sabes ya! assesses students' acquisition via a more communicative approach (information gap activities or multiple-choice input activities). In the third and fourth chapters, the focus is narrowed down to common spelling errors due to false cognates in Spanish and English practiced with traditional output activities, inductive and deductive approaches with a focus on form and the differences between them, and diacritics such as homophones are assessed through input activities.

In the sixth chapter the distinction between ' $r$ ' and ' $r$ ' is presented using an authentic text and focusing on the phonetic distinction between these phonemes. Input activities are used for practice to distinguish between their phonemic categorization (vibrante simple versus vibrante multiple) and true/false metalinguistic sentences assess their awareness of the differences between both phonemes. Then, the spelling rules are explained providing examples followed by drills, input translation activities, and even pronunciation of popular tongue-twisters for practice. In chapter seven, traditional drills are selected for the spelling of verbs that ends up being problematic for Spanish heritage speakers (different spelling but not pronunciation): e.g. $g / j, g / g u, g u / g, g u / g \ddot{u}, c / z, i / y, c / q u$.

\subsection{Conversaciones escritas}

The author explains that the rules of accentuation are included in the workbook and teaches students to use the spellchecker in Spanish. The textbook provides structured practice with the errors that the spellchecker does not recognize (mainly diacritics). All the activities are integrated into the chapter topics. In this textbook, orthography is included within the section called Gramática y uso. In the first chapter there is a guide about how to use the spellchecker in Spanish and how to insert accents with an English keyboard, written accents in diacritics and homonyms are integrated into the immigration topic. Then, a letter to Jorge Ramos is presented to revise the errors that spellcheckers do not catch. Again, in Entrando a la conversación, there is a follow-up activity consisting of a letter that needs to be spellchecked by students. In Gramática y uso the focus is the diacritics with the third person singular in the preterit. These are practiced via input activities, followed by a fill-in- 
the blank output activity with a cierto/falso comprehension check follow-up, all of this thematically related to the previous reading. Right after, accentuation with homonyms is introduced through a table with meaning distinction and examples. The practice is done via accent insertion in sentences with homonyms, then a translation of sentences containing them with a focus on written accents, and a final step for meaning comprehension. Then, we can find a revision of the lyrics of a song to practice using the spellchecker. There is a focus on accentuation and spelling throughout the textbook in the writing guidelines. In chapter two, the differences between $h a$ and $a$ are integrated into the reading of immigration. It is a noticing input activity, where students have to identify those homonyms in a text followed by a table with the uses of $h a$. Then, a follow-up true-false input activity is given. In Gramática y uso, $a$ in verbal periphrasis is explained since the spellchecker does not catch this error. An input activity is used to make students aware of the contexts where $a$ might be forgotten and a translation output activity follows this. Simple selection is used for focus on form of $a / h a$. The next point covered in this section is accentuation: more examples that the spellchecker does not catch are given such as diacritics and interrogative questions. An input activity follows for practice with options given in English. In chapter three, more verbal diacritics are presented. A structured input processing activity to distinguish between preterit and subjunctive is given, but this time students are expected not only to choose the right form in context but also to indicate the name of the tense. Afterwards, an insertion of written accents activity in sentences with bolded verbal forms is offered. In chapter six we find the differences between the insertion and deletion of the written accent for the future tense or the past subjunctive forms. There is a table with examples to notice the differences between both tenses. Then, there is the explicit rule to be completed by students. Again, processing instruction is the teaching technique used to practice both forms. Then, an output activity is created where students write sentences about the future and the past.

\subsection{El mundo 21 hispano}

In the first chapter the syllable is introduced. Rules are defined through examples. The difference with respect to the other textbooks is that the practice of syllabification consists of word lists given by the instructor instead of by the student directly. The accentuation rules depending on the stressed syllable are presented, followed by dictation practice. Finally, there is a contextualized activity of inserting written accents in a paragraph. Grammar and spelling are integrated in the teaching of nouns and the formation of plurals with examples of common spelling errors. At the end of this chapter diphthongs and triphthongs are defined with examples and dictation is used again for practice. Following the same structure, the last activity is contextualized for correcting syllabification and accentuation errors. At the end of every chapter there is a review. Within this section, one of the activities was a contextualized multiple-choice input activity on 
diacritics. However, there is no previous explanation or presentation of them until chapter two where they are presented via examples and short explanations. Again, practice is performed through dictation and a final paragraph for written accents insertion. Spelling is integrated in assorted sections of the chapter such as the short movie included in every chapter. As part of the "After watching the video" section, there is a follow-up drill of the spelling changes in the conjugation of the present tense. Later on in the chapter, we can find the explicit explanation of the spelling changes in the present tense. Before the explicit explanations, there is a grammaticality judgment input introduction for heritage learners to check their native intuitions. There are also other common spelling errors mentioned in this chapter such as the grapheme 'c'. Input and output activities follow the practice for this through dictation. The last activity is a paragraph where students must correct the spelling errors.

There is an explanation provided by the authors about the rationale behind these errors specifically addressed to the audience (mentioning lack of formal instruction in Spanish by American heritage speakers of Spanish). There is an attempt for a communicative approach such as an interactive activity on spelling and accentuation error correction in a letter from a peasant to show differences across registers. In chapter three, the focus is on how to write $/ \mathrm{k} /$ and $/ \mathrm{s} /$. Practice through dictation of word completion and a final written accent insertion paragraph as a review is offered. However, perhaps it would be more cohesive to have a similar activity for $/ \mathrm{k} /, / \mathrm{s} /$, spelling error correction. At the end of this chapter, the graphemes ' $s$ ' and ' $z$ ' are examined through examples. Again, word completion dictation is the technique used for practice. After, the preterit verbal forms spelling changes are explained through examples and typical errors made by Spanish heritage speakers due to rule overgeneralization such as buscé or llegé. An input activity with diacritics with the preterit form is chosen to wrap up the preterit. The next spelling error covered in this chapter is the problems that ' $g$ ' $y$ ' $j$ ' and the phonemes $/ g /$ and $/ \mathrm{x} /$ present. Through dictation, word completion and input activities for sound recognition follow a list of examples with the bolded target grapheme. My impression is that students might get confused with the distinction between graphemes, phonemes and sounds so instructors might need to emphasize this distinction and the effect of these differences on orthography.

In chapter four the differences between ' $b$ ' and ' $v$ ' are studied. The distribution of the stop and fricative allophones are explained in more student-friendly terms such as soft and strong pronunciation. There is a listening input activity to practice the distinction between these two allophones first. Then, rules are explained and finally there is a word-completion output activity. As part of the section Nuestra lengua en uso, homophones are listed with contextualized examples. Students practice through an input activity of a paragraph containing homophone options and an output activity in which students have to compose sentences to distinguish homophones. The grapheme ' $x$ ' is introduced through its different phonemes. Multiple-choice input dictation activities are used to make grapheme-sound 
connections. Then, rules are presented followed by output activities of word completion. In chapter five, the problematic grapheme is ' $\mathrm{j}$ '. There is an explanation followed by examples and a dictation output activity of word completion and a paragraph for error correction. The subjunctive is introduced in this chapter, and subsequently spelling changes are mentioned. There are also notes for Spanish heritage speakers with a common use of the accentuation on the antepenultimate syllable instead of the penultimate of the present subjunctive, e.g. hágamos vs. hagamos. A contextualized input activity is used for practice. In Así hablamos $y$ asi escribimos, the focus is on the grapheme ' $\mathrm{g}$ ' and the 'ge', 'gi' pronunciation. For practice, there are several traditional output activities of word completion. In chapter six the grapheme ' $h$ ' is covered through a brief explanation and examples. As usual, word completion dictation activities are used for practice followed by an error correction paragraph integrated with the cultural component of the chapter. Then, the usage of the grapheme ' $y$ ' is explained and practiced via an input dictation activity to distinguish between /i/ and /y/. Word completion and a paragraph of error correction is at the end of this section.

In chapter seven the grapheme studied is ' 11 '. The practice for this is word completion and error correction with ' 11 ' words. Graphemes appear in order depending on the point of articulation of the sounds they represent. Therefore, ' $r$ ' and 'rr' are next. There is an input activity for sound discrimination. Word completion activities and a distinction between minimal pairs follow this. In chapter eight, two homophones (ay and hay) are presented. After a definition of homophones and several contextualized examples, the practice is a multiple-choice audio input activity and an output dictation activity. Finally, an error correction paragraph is given. Then, under Nuestra lengua en uso, examples of spelling errors due to English transference are offered. Afterwards, a letter from a peer heritage speaker of Spanish is presented with typical spelling errors for correction. Other homophones are introduced next such as certain diacritics (de/dé; el/él). This time a list is given with the two variants and their distinct meaning. Via dictation, the homophone is mentioned and the grammatical function is given so that students can make the connection between form and function or form and meaning. In the next activity, there is a fill-in-theblank dictation activity where students have to make form-meaning connections.

In chapter nine $a, a h, h a$ homophones are explained. Similar practice is given: a multiple-choice audio input activity, a fill-in-the blank audio activity, and a paragraph for error correction. The diacritics esta and está are studied next with similar strategies: an audio input activity and fill-in-the blank sentences.

In chapter ten there is a review of syllabification and accentuation rules and practice. There is one single activity to review both rules. Via dictation, students have to divide words into syllables and underline the stressed syllable. Then, written accents must be inserted as needed. In the second part of the chapter, there is another review: accentuation, diphthongs, and triphthongs. Rules are summarized in an explicit form and practice is very 
similar with an identical syllabification and accentuation exercise and a written accent insertion in sentences.

\section{DISCUSSION}

After the analysis of the aspects of orthography and techniques used to teach orthography in these textbooks (analyzed in chronological order), a summary is provided in the following tables to get a clearer overview of these textbooks' proposals:

\begin{tabular}{|c|c|c|c|c|}
\hline Orthography & Entre mundos & Sí se puede & $\begin{array}{c}\text { Conversaciones } \\
\text { escritas }\end{array}$ & Mundo 21 \\
\hline Syllabification & YES & YES & $\mathrm{NO}$ & YES \\
\hline Common spelling errors & YES & YES & YES & YES \\
\hline $\begin{array}{llr}\text { Spelling } & \text { changes } & \text { in } \\
\text { indicative: } & \text { present } & \text { tense, } \\
\text { preterit, } & \text { future, } & \text { or } \\
\text { conditional } & & \\
\end{array}$ & YES & YES & YES & YES \\
\hline Capitalization/Punctuation & YES & YES & NO & NO \\
\hline Accentuation rules & YES & YES & YES & YES \\
\hline Diacritics & YES & YES & YES & YES \\
\hline $\begin{array}{lll}\begin{array}{l}\text { Spelling } \\
\text { commands }\end{array} & \text { changes in } \\
\end{array}$ & YES & $\mathrm{NO}$ & NO & NO \\
\hline Diphthong accentuation & YES & YES & NO & YES \\
\hline $\begin{array}{l}\text { Spelling changes in } \\
\text { subjunctive: present or past }\end{array}$ & YES & NO & YES & YES \\
\hline
\end{tabular}

Table 1: Orthography taught in these textbooks

All the textbooks include a focus on common spelling errors, as Beaudrie (2012) suggested, and on accentuation rules (with an emphasis on diacritics) along the lines of the scarce research on orthography. Sí se puede emphasizes the difference in spelling in terms of word categories (such as verbal forms) and Conversaciones escritas focuses on the spelling errors that the spellchecker does not recognize, assuming that modern-day students do not usually handwrite in academic Spanish, so they only need to know how to type without errors. Therefore, coherently, the author does not specifically cover syllabification or capitalization or punctuation. In the same line, Mundo 21, the most recent textbook of these four, follows the same trend not going over capitalization/punctuation or spelling changes in commands.

Regarding teaching techniques, there is an attempt to use a communicative approach, especially in Conversaciones escritas, through input-output activities and comprehension 
checks. Nevertheless, there are still remnants of traditional explicit explanations and drills for orthography instruction in all the textbooks to a greater or lesser degree. In Entre mundos, for example, we find a repeated question-answer format so that students can deduce orthographic rules. Nevertheless, in a communicative language class the traditional presentation production practice model by Larsen-Freeman (2003) is no longer recommended since the explicit rule presentation followed by drills or decontextualized activities does not encourage students to go through the cognitive processes that are necessary so that grammar acquisition can take place (Fernández, 2011). The remaining question is whether this can also apply to orthography acquisition.

Fortunately, we can perceive a trend in the textbooks towards being more communicative over time with contextualized activities thematically integrated in every chapter and offering more opportunities for interaction. In fact, Conversaciones escritas and Mundo 21 hispano seem to offer more communicative opportunities than the older textbooks through assorted strategies such as noticing and comprehensible input to facilitate learners to make form-meaning connections. Thus, these textbooks suggest that the focus on form strategies commonly used for grammar acquisition in the L2 classroom might be also transferred to the heritage classroom even if it is for orthography instruction as shown in the following table.

In Table 2, we analyze assorted activities and strategies used in these textbooks to teach orthography:

\begin{tabular}{|l|l|l|l|l|}
\hline & \multicolumn{1}{|c|}{ Entre mundos } & \multicolumn{1}{|c|}{ Sí se puede } & Conversaciones & \multicolumn{1}{|c|}{ Mundo 21 } \\
\hline $\begin{array}{l}\text { Input } \\
\text { (matching/simple } \\
\text { selection/multiple } \\
\text { choice) }\end{array}$ & $Y E S$ & YES & YES & YES \\
\hline Fill-in-the-blanks & $Y E S$ & $Y E S$ & $Y E S$ & YES \\
\hline Dictation & $Y E S$ & NO & NO & YES \\
\hline $\begin{array}{l}\text { Question/Answer/ } \\
\text { knowledge }\end{array}$ & $Y E S$ & $Y E S$ & NO & NO \\
\hline Drills & $Y E S$ & $Y E S$ & NO & NO \\
\hline Translation & NO & $Y E S$ & $Y E S$ & NO \\
\hline $\begin{array}{l}\text { Sentence or word } \\
\text { completion }\end{array}$ & NO & NO & NO & YES \\
\hline Error correction & NO & NO & $Y E S$ & \\
\hline
\end{tabular}

Table 2: Activities and Strategies for orthography instruction 
All the textbooks offer input opportunities, required for acquisition, mainly in the multiple-choice format. The next typical activity was the traditional fill-in-the blank, offered by all textbooks. Interestingly, dictation was chosen by the oldest textbook Entre mundos and the most recent one Mundo 21 hispano, being the most common activity for the latter. This technique goes along the lines of research by Pyun et al. (2011). In the oldest textbooks, Entre mundos and Sí se puede, there is a focus on metalinguistic knowledge, specifically via an explicit question-answer format. Drills are avoided in the most recent textbooks, what shows a tendency towards leaving traditional instruction behind and replacing it with product-oriented approaches (e.g. controlled oral practice for syllabification or the identification of the stressed syllable in Entre mundos) towards a more acquisition-based communicative approach (e.g. diacritics in Conversaciones escritas). Moreover, there is a preference for error correction in these textbooks, suggesting the importance of review and feedback on this matter. On the other hand, sentence and word completion seems to be the least popular activity among these textbooks.

Finally, it is necessary to note that even though some of these activities (communicative or not) are commonly found in grammar instruction such as multiplechoice, fill-in the blanks or merely drills, there are some recurrent activities across these textbooks that characterize the specifics of current approaches to orthography instruction such as dictation, error correction, output based question-answer format, and translation. The rationale behind these strategies is not very clear yet due to the lack of research in this area, but the existing research suggests at minimum the effectiveness of dictation. By establishing a parallelism between successful teaching techniques for grammar instruction (input- and output-based), it is interesting to notice how typical input-based activities for grammar instruction are also implemented in orthography instruction, whereas other typical output based activities like dictogloss or input/output cycles are not.

Due to the increase of Spanish heritage learner presence in higher education, we can be hopeful about a greater advance in instructional research in the future and the expectation of more communicative approaches for heritage learner instruction. However, a consensus between textbooks and research is at some points difficult to reach. As Fernandez (2011) observed in a study on grammar approaches in L2 beginning textbooks, traditional approaches are still present in textbooks regardless of research in the field since publishers work along instructors' expectations. There are many reasons behind these expectations that sometimes make instructors reluctant to change. One of them might be found in the confusion surrounding the definition of "communicative" (interpretation, negotiation, and expression of meaning) as VanPatten (1998) claimed. Thus, Fernández argued communication is inaccurately measured by the amount of production activities. She proposed professional development and training as a solution to this. In the case of heritage learners, it is crucial that instructors be specifically trained to teach this student population from a sociolinguistic perspective, as it is well-known in the field. However, to my 
knowledge, this not always the case in many institutions due to the recency of the heritage learners' programs or even courses in most cases.

\section{CONCLUSIONS}

Even though heritage learners' instruction is still an emerging field in Spanish language teaching, most of the focus has been on general approaches to Spanish heritage learners' sociolinguistic background instead of focusing on the hardest challenges for these learners: literacy skills with an emphasis on orthography. Four well-known textbooks from 2003 to 2014 have been analyzed to shed light on the current approaches to orthography instruction. Results show that despite many decontextualized activities and explicit rule presentation to raise students' metalinguistic awareness following traditional approaches, there is an ascending tendency to use more communicative approaches with a focus on form and input-output activities (mainly Conversaciones escritas), following the research in the field. This entails a focus on common spelling errors done in all textbooks (Beaudrie, 2012) and dictation as an effective strategy (Pyun et al, 2011), mainly in Entre mundos and Mundo 21 hispano. In general terms, some of the current strategies effectively used in the L2 classroom are also implemented in the heritage classroom (input- and output-based: e.g. multiple choice, fill-in-the-blank) but, ironically, despite the abundance of production activities in these textbooks, we cannot find examples of common output-based activities such as dictogloss or input-output cycles.

\section{REFERENCES}

AlOnso-LyRINTZIS, Deanna and Brandon ZASLOW (2003): Entre Mundos: An Integrated Approach For The Native Speaker. $2^{\text {nd }}$. Edition. Upper Saddle River, NJ: Pearson Prentice Hall, <http://dx.doi.org/10.2307/328715>.

ANDERSON, Jim (2008): «Towards an integrated second-language pedagogy for foreign and community/heritage 1 languages in multilingual Britain», Language Learning Journal, 36 (1):79-89, <http://dx.doi.org/10.1080/09571730801988553>.

APEL, Kenn (2009): «The acquisition of mental orthographic representations for reading and spelling development», Communication Disorders Quarterly, 31(1):42-52, <http://dx.doi.org/10.1177/1525740108325553>.

BEAUDRIE, Sara (2007): «La adquisición del acento ortográfico en la clase de español como segunda lengua», Hispania, 90(4):809-823, 〈http://dx.doi.org/10.2307/20063614〉. 
BEAUDRIE, Sara (2012): «A corpus-based study on the misspellings of Spanish heritage learners and their implications for teaching», Linguistics and Education, 23(1):135144, 〈http://dx.doi.org/10.1016/j.linged.2011.09.001>.

BERMEL, Neil and Olga KAGAN (2000): «The maintenance of written Russian in heritage speakers». The learning and teaching of Slavic languages and cultures, 405-436.

Bowles, Melissa (2011): «Exploring the Role of Modality: L2-Heritage Learners Interactions in the Spanish Language Classroom», Heritage Language Journal, 8 (1):30-65.

BRown, Alan (1990): «A review of recent research on spelling», Educational Psychology Review, 2 (4):365-397, 〈http://dx.doi.org/10.1007/bf01323630>.

CARreIRA, María (2002): «When phonological limitations compromise literacy: A connectionist approach to enhancing the phonological competence of heritage language speakers of Spanish», in S. Hammadou (Ed.), Literacy and the second language learner. Greenwich, CT: IAP.

CARreIrA, María and Michelle GEOFFrIOn-VInCI (2008): Sí se puede: Un curso transicional para hispanohablantes. Boston, MA: Houghton Mifflin.

Chevalier, Joan (2004): «Heritage language literacy: Theory and practice», Heritage Language Journal, 2 (1):1-19.

DAVIS, Paul and Mario RINVOLUCRI (1988): Dictation: New methods, new possibilities. Ernst Klett Sprachen, <http://dx.doi.org/10.2307/326886>.

DEKEYSER, Robert (1995): «Learning second language grammar rules», Studies in second language acquisition, 17 (3):379-410, 〈http://dx.doi.org/10.1017/s027226310001425x > .

EHRI, Linnea (2000): «Learning to read and learning to spell: Two sides of a coin», Topics in Language Disorders, 20(3):19-36, <http://dx.doi.org/10.1097/00011363200020030-00005>.

ELLIS, Nick (1993): «Rules and instances in foreign language learning: Interactions of explicit and implicit knowledge», European Journal of Cognitive Psychology, 5(3),289-318, 〈http://dx.doi.org/10.1080/09541449308520120>.

FERNÁNDEZ, Claudia (2011): «Approaches to grammar instruction in teaching materials: A study in current L2 beginning-level Spanish textbooks», Hispania, 94 (1):155-170.

Grompone, María A. CARbonell (1982): Un sistema interpretativo de la ortografía. Teoría y técnicas para la comprensión del lenguaje escrito. Santiago: UNICEF, Ediciones Universidad Católica.

Guion, Susan, Tetsua Harada and J.J. Clark (2004): «Early and late Spanish-English bilinguals' acquisition of English word stress patterns», Bilingualism: Language and Cognition, 7(3):207-226, <http://dx.doi.org/10.1017/s1366728904001592>.

HENRY, Edgardo (1983): «Dificultades en la percepción del acento», RLA: Revista de lingüística teórica y aplicada, 21, 65-80. 
Justicia, Fernando, Sylvia, Defior, Santiago Pelegrina and Francisco Martos (1999): «The sources of error in Spanish writing (Research Note)», Journal of Research in Reading, 22 (2), 198-202, <http://dx.doi.org/10.1111/1467-9817.00082>.

KIM, Hi-Sun Helen (2001): «Issues of heritage learners in Korean language classes. The Korean Language in America», 6, 257-274.

KagAN, Olga and Kathleen DiLlon (2001): «A new perspective on teaching Russian: Focus on the heritage learner», Slavic and East European Journal, 507-518.

LARSEN-FREEMAN, Diane (2003): Teaching Language: from Grammar to Grammarian. Boston: Thomson-Heinle.

LOEWEN, Donald (2008): «Overcoming aural proficiency: Pitfalls for heritage learners in Russian cyberspace», Heritage Language Journal, 6(1):23-39.

LORD, Gillian (2002): The Second Language Acquisition of Spanish Stress: Derivational, Analogical or Lexical?, Unpublished Doctoral Dissertation: Penn State University.

LYSTER, Roy (2004): «Differential effects of prompts and recasts in form-focused instruction», Studies in second language acquisition, 26(3):399-432, <http://dx.doi.org/10.1017/s0272263104263021 >.

MiKULSKI, Ariana (2006): «Accent-uating Rules and Relationships: Motivations, Attitudes, and Goals in a Spanish for Native Speakers Class», Foreign Language Annals, 39(4):660-682, 〈http://dx.doi.org/10.1111/j.1944-9720.2006.tb02282.x >.

MONTRUL, Silvina and Melissa Bowles (2008): «Negative evidence in instructed heritage language acquisition: A preliminary study of differential object marking», in Proceedings of the 2007 Second Language Research Forum, 252-262.

PoTOWsKi, Kim (2005): Fundamentos de la enseñanza del español a los hablantes nativos en los Estados Unidos. Madrid: Arco Libros.

PotowsKi, Kim (2010): Conversaciones Escritas: Lectura y redacción en contexto. Hoboken, NJ: John Wiley.

Pyun, Danielle and Angela LEE-SMith (2011): «Reducing Korean heritage language learners' orthographic errors: the contribution of online and in-class dictation and form-focused instruction», Language, Culture and Curriculum, 24(2):141-158, <http://dx.doi.org/10.1080/07908318.2011.582952>.

ROBINSON, Peter (1996): «Learning simple and complex second language rules under implicit, incidental, rule-search, and instructed conditions», Studies in Second Language Acquisition, 18(1):27-67, <http://dx.doi.org/10.1017/s0272263100014674>.

SAMANIEGO, Fabián, Nelso RoJas, Francisco NoGAles and Mario DE AlarCón (2013): El mundo 21 hispano. Boston: Cengage Learning.

TAPFER, Anna Patricia (2013): Heritage learners in the classroom: an investigation into German heritage learners' misspellings, Master Thesis.

TEMPLETON, Shane and Darrell MORRIS (2001): «Reconceptualizing spelling development and instruction», Reading Online, 5(3), n. 3. 
TESCHNER, Richard (1971): «The Written Accent in Spanish: A Programmed Lesson», Hispania, 54(4):885-894, 〈http://dx.doi.org/10.2307/338183〉.

URRIA, Adriana (1988): «Una experiencia pedagógica sobre ortografía acentual», Argentina: Lectura y Vida, 9.

VAN PATTEN, Bill (1998): «Perceptions and perspectives on the term "communicative"», Hispania, 81(4):925-932, <http://dx.doi.org/10.2307/345805>.

VALETTE, Rebecca (1964): «The use of the dictee in the French language classroom», The Modern Language Journal, 48 (7):431-434.

WhitaKer, S. F. (1976): «What is the Status of Dictation?», Audio-Visual Language Journal, 14, 87-93.

WIECZOREK, Joseph (1991): «The Significance of Written Accent Marks for L2 Learners of Spanish», Georgetown Journal of Languages and Linguistics, 2 (2):176-90. 